\title{
Avaliação da Progressão Cognitiva no Internato de Clínica Médica
}

\author{
Evaluation of the Cognitive Progress During \\ Medical Internship
}

\author{
Sávio Silva Santos ${ }^{I}$ \\ Rodrigo Siqueira-BatistaII \\ Andréia Patrícia Gomes ${ }^{I I I}$ \\ Loriléa Chaves de Almeida ${ }^{I V}$ \\ Lúcia Brandão de Oliveira ${ }^{I V}$ \\ Rodolpho Jacques M. FarinazzoIV \\ Sérgio Pettendorfer ${ }^{I V}$ \\ Luiz Felipe da Silva Pinto ${ }^{I V}$
}

\section{PALAVRAS-CHAVE \\ - Educação Médica; \\ - Internato; \\ - Avaliação.}

\section{KEY WORDS}

- Medical Education;

- Internship

- Evaluation.

Aprovado em: 05/11/2007
390 REVISTA BRASILEIRA DE EDUCAÇ̃̃o MÉDICA
${ }^{1}$ Fundação Educacional Serra dos Órgãos, Rio de Janeiro, Brasil; Sociedade Brasileira de Clínica Médica, Brasília, Brasil.

${ }^{\prime \prime}$ Fundação Educacional Serra dos Órgãos, Rio de Janeiro, Brasil; Universidade Federal do Rio de Janeiro, Rio de Janeiro, Brasil.

${ }^{\text {III }}$ Fundação Educacional Serra dos Órgãos, Rio de Janeiro, Brasil; Secretaria de Estado de Saúde, Rio de Janeiro, Brasil.

${ }^{\text {IV }}$ Fundação Educacional Serra dos Órgãos, Rio de Janeiro, Brasil. 


\section{INTRODUÇÃO}

O internato é o momento do curso de graduação em que o estudante de Medicina experimenta, de forma genuína, o saberfazer cotidiano da profissão ${ }^{1,2}$. Além disso, a estrutura proposta de estágio teórico-prático nas grandes áreas básicas do conhecimento médico - Clínica Médica, Clínica Cirúrgica, Ginecologia e Obstetrícia, Pediatria e Saúde Coletiva - é capaz de proporcionar ao aluno a possibilidade de um contato mais íntimo com diferentes campos do saber médico, favorecendo a construção de um horizonte mais amplo para o exercício da medicina, sob uma perspectiva generalista, ao mesmo tempo em que constitui um importante momento para melhor escolha da especialidade.

Neste âmbito se insere o Internato de Clínica Médica (ICM), por sua relevância tanto nas especialidades de área clínica, quando nas demais, uma vez que é tradicionalmente na Clínica Médica que se exercita, de forma sistemática, a colheita e organização de informações, análise e diagnóstico, esteio primordial para a boa atividade do médico. Sob esta perspectiva, no curso de graduação em Medicina da Fundação Educacional Serra dos Órgãos (Feso), tem-se a preocupação de estimular a consolidação do raciocínio clínico a partir de três liames fundamentais: (1) treinamento em serviço — no Hospital de Clínicas de Teresópolis Costantino Ottaviano (HCTCO-Feso); (2) aquisição de consistente formação teórica; e (3) estímulo à reflexão crítica sobre os conteúdos e práticas do estudante.

Como relevante preocupação no curso tem-se também a avaliação do aprendizado dos alunos, elemento constitutivo de todo processo educacional ${ }^{3,4}$. A avaliação durante o Internato de Clínica Médica é realizada por meio dos seguintes quesitos:

- Assiduidade e pontualidade;

- Cuidados dispensados aos pacientes;

- Interesse nas discussões e bom relacionamento com os colegas e com a equipe do hospital;

- Qualidade das anamneses nas papeletas;

- Sessões clínicas (participação de todos os internos);

- Presença nos seminários "Filosofia, Saúde e Cultura", organizados pelo Núcleo de Estudos em Filosofia e Saúde (Nefisa);

- Participação nos "pegas";

- Participação nos seminários, nos quais assuntos predeterminados são apresentados pelos estudantes;

- Número de acertos dos "Casos da Semana", afixados no mural do internato;

- Conceito das enfermarias e do plantão (CEP);

- Conceito nas dramatizações mensais organizadas pelos discentes, nas quais são enfocados temas de ética médica e bioética;
- Conceitos nas atividades mensais de Cinema \& Medicina;

- Conceito da Tutoria (CT);

- Nota no Pré-Teste Geral (PTG), constituído por questões das provas de módulo anteriores: $20 \%$ serão agregados à nota da prova final do módulo;

- Notas nos pré-testes e nas atividades das "Oficinas" (atividades das tardes de $3^{\mathrm{a}}, 4^{\mathrm{a}}$, $5^{\mathrm{a}}$ e $6^{\mathrm{a}}$ feira): será agregado $0,5 \%$ à nota da prova final. Faltas terão conseqüências negativas na avaliação;

- Prova de Módulo (acrescida pelos pré-testes = PM).

A nota final (NF) do interno deverá ser igual ou superior a 6,0, sendo calculada pela seguinte fórmula:

$$
\mathrm{NF}=\frac{[(\text { média de CEP }+\mathrm{CT}) / 2]+\mathrm{PM}}{2}
$$

A diferença entre o grau obtido no Pré-Teste Geral e na Prova de Módulo é capaz de dar a dimensão do nível de apreensão cognitiva do estudante, uma vez que (1) ambas versam sobre os mesmos conteúdos, (2) são preparadas sempre pelos mesmos docentes e (3) o primeiro é sempre constituído por questões pertencentes a provas de módulo anteriores (às quais os estudantes não têm mais acesso, uma vez que a mesma não é devolvida).

Com base nestes pressupostos, o objetivo do presente artigo é apresentar dados acerca da progressão cognitiva no ICM, a partir da comparação entre estes dois momentos da avaliação.

\section{MÉTODOS}

\section{Local do estudo}

O Hospital de Clínicas de Teresópolis Costantino Ottaviano (HCTCO) é o hospital-escola dos cursos de graduação em Medicina, Enfermagem e Fisioterapia da Fundação Educacional Serra dos Órgãos. A unidade hospitalar possui 178 leitos para internação de pacientes conveniados com o SUS e 21 leitos para internação de pacientes particulares.

\section{Período de estudo}

O trabalho abrange o período de janeiro de 1999 a dezembro de 2004, que compreende 24 rotatórios do internato (cada um com três meses). O internato médico na Fundação Educacional Serra dos Órgãos tem duração de 18 meses (três meses em cada uma das áreas básicas - Clínica Médica, Ginecocologia e Obstetrícia, Cirurgia e Pediatria - , dois meses no opcional e quatro meses no Programa de Saúde da Família). 


\section{População}

A população compreende 669 internos, sendo 329 do $12^{\circ}$ período e 340 do $11^{\circ}$ período - em torno de 30 alunos por período estudado.

\section{Programação do internato}

As atividades do Internato de Clínica Médica são distribuídas da seguinte forma:

- Manhãs (8h00-10h30) de segunda a sexta-feira: atividade prática, caracterizada pelo cuidado aos pacientes internados nas enfermarias do Serviço de Clínica Médica do HCTCOFeso, sob a supervisão de médicos e professores da instituição, atuando nas diferentes etapas de diagnóstico, tratamento e estabelecimento de relação médico-paciente;

- Manhãs (10h30-12h00) de segundas, quintas e sextasfeiras: discussão dos principais casos das enfermarias do HCTCO-Feso com os tutores do internato - professores Sávio Silva Santos e Rodrigo Siqueira Batista - em dois grupos de alunos; nesta atividade, dá-se grande ênfase à discussão da história da doença atual;

- Manhãs (10h30-12h00), às terças-feiras: seminários sobre temas de Clínica Médica, nos quais são apresentados casos clínicos elaborados (ou vivenciados) pelos internos, sob a coordenação dos professores Sávio Silva Santos e Rodrigo Siqueira Batista; a atividade poderá valer nota individual, sendo acrescida à Prova de Módulo um percentual a ser determinado pelos tutores; algumas terças-feiras são dedicadas a atividades de dramatização, discussão de filmes e conferências sobre arte;

- Manhãs (10h30-12h00), às quartas-feiras: visita aos pacientes, com a presença dos professores lotados no HCTCO, nas respectivas clínicas. A visita poderá ter dois momentos: num primeiro, cada interno deverá fazer um breve relato da condição atual dos cuidados com seu paciente, resumindo as providências necessárias à continuidade destes cuidados; num segundo momento, casos complexos serão discutidos à parte. Nas duas situações, a discussão não é realizada em presença do paciente (por motivos óbvios);

- Tardes (14h00-18h00) de segunda a sexta-feira: realização de uma oficina sobre temas de Clínica Médica considerados mais importantes, relacionados no Quadro 1. Cada oficina é precedida por breve exposição docente, mas o crucial neste momento é o trabalho dos internos em pequenos grupos, geralmente de cinco a seis, supervisionados por dois tutores. Este trabalho consiste basicamente em resolução de questões e discussão de casos clínicos, facultando-se e incentivando-se a consulta ampla a livros, revistas e internet. Antes do início das atividades se realiza um pré-teste sobre o assunto da oficina;
- Plantão semanal de 12 horas no Serviço de Emergência do HCTCO, sendo o interno supervisionado por médicos da instituição. O turno diurno terá uma duração menor, iniciando-se às $8 \mathrm{~h} 00$ e terminando às $13 \mathrm{~h} 00$, para que os internos possam participar das oficinas;

- Plantão de 12 horas nos fins de semana, em caráter rotatório;

- Participação, como ouvintes, dos seminários "Filosofia, Saúde e Cultura" do Núcleo de Estudos em Filosofia e Saúde (Nefisa-Feso), com periodicidade mensal;

- Participação, como relatores, das sessões clínicas da disciplina de Clínica Médica do HCTCO-Feso, sempre realizadas na terceira sexta-feira de cada mês (10h00-12h00); estas sessões contam com a presença e participação dos médicos residentes e dos professores.

\section{QUADRO 1}

Assuntos contemplados no Internato de Clínica Médica do HCTCO-Feso, a partir dos quais são elaborados o PTG e a PM

\begin{tabular}{|c|c|}
\hline Acidente vascular encefálico & Hemocromatose \\
\hline Aids & Hemorragia digestiva \\
\hline Anemias & Hepatites virais \\
\hline Angina & Hipertensão arterial sistêmica \\
\hline Artrite reumatóide & Hipertiroidismo \\
\hline Ascite & Hipotiroidismo \\
\hline Asma brônquica & Icterícias \\
\hline Bacteriologia clínica & Imunologia básica para o clínico \\
\hline Bioética & Infarto agudo do miocárdio \\
\hline Bradiarritmias & Infecção do trato urinário \\
\hline Câncer de cólon & Infecções transfusionais \\
\hline Câncer de próstata & Insuficiência cardíaca \\
\hline Câncer de pulmão & Insuficiência renal aguda \\
\hline Câncer de tiróide & Insuficiência renal crônica \\
\hline Câncer gástrico & Insuficiência respiratória \\
\hline Cardiomiopatias & Lesões orovalvares \\
\hline Choque & Leucemias \\
\hline Cirrose hepática & Linfomas \\
\hline Critérios para hemotransfusão & Lupus eritematoso sistêmico \\
\hline Diabetes mellitus & Meningites \\
\hline Dispepsia & Pancreatites \\
\hline Doença do refluxo & Pericardite \\
\hline gastroesofágico & Pneumonia \\
\hline Doença inflamatória intestinal & Reanimação cardiorrespiratória \\
\hline Doença ulcerosa & Reações de hipersensibilidade \\
\hline Doenças da supra-renal & Sepse \\
\hline Eletrocardiografia & Síndrome de derrame pleural \\
\hline Embolia pulmonar & Síndromes demenciais \\
\hline Endocardite infecciosa & Síndromes extrapiramidais \\
\hline Ética médica e deontologia & Taquiarritmias \\
\hline Exame do abdome & Terapia antimicrobiana \\
\hline Exame neurológico & Tuberculose \\
\hline Exame do tórax & Vasculites \\
\hline Febre reumática & \\
\hline
\end{tabular}




\section{GRÁFICO 1}

Comparação do desempenho cognitivo no Internato de Clínica Médica da Feso de 1999 a 2004 (n = 606)

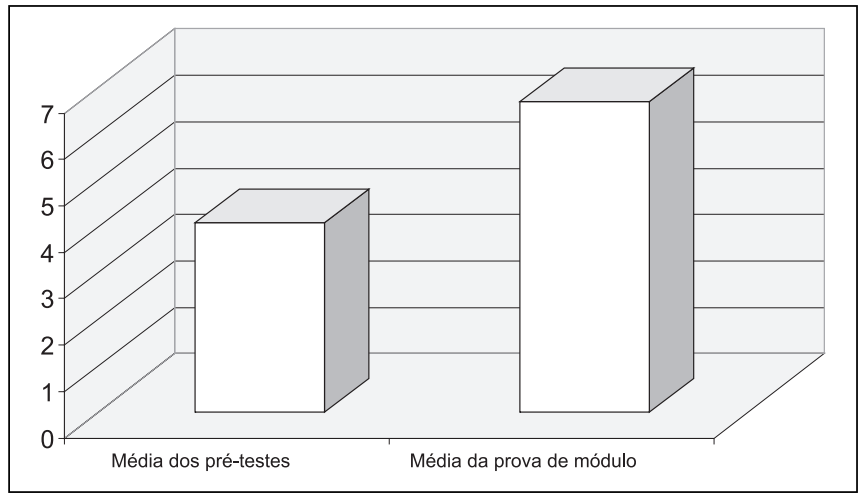

\section{Avaliações investigadas}

Os testes de desempenho cognitivo comparados foram:

- Pré-teste Geral (PTG), realizado no primeiro dia do internato e elaborado a partir de questões prévias da Prova de Módulo. É constituído por 12 perguntas de múltipla escolha - das quais dez versam sobre temas de Clínica Médica e duas sobre Ética e Bioética - , com cinco opções cada, e quatro discursivas com quatro itens cada. Todas as questões são elaboradas com base em casos clínicos, que, no enunciado e nas assertivas, abordam diferentes assuntos da área de Clínica Médica (Quadro 1); as de múltipla escolha valem meio ponto cada, e as discursivas um ponto, totalizando dez pontos possíveis. $\mathrm{O}$ tempo para realizar a atividade é de duas horas.

- Prova Final de Módulo (PM), a qual tem estrutura e tempo para realização iguais aos do PTG.

\section{Critério para comparar as duas formas de avaliação}

Foram comparados os resultados obtidos nas avaliações de internos que realizaram necessariamente ambos os testes, o PTG e a PM.

\section{Tratamento dos dados}

O banco de dados constituído no programa Epiinfo do Center for Disease Control and Prevention (CDC) foi analisado por meio deste mesmo software. No tratamento estatístico, foram utilizados a análise das freqüências, o teste do qui-quadrado $\left(\mathrm{C}^{2}\right)$, o teste exato de Fisher e o teste t-Student $^{5}$. Foram considerados como significância estatística valores de probabilidade de significância ( $\mathrm{p}$-valor) menores que 0,05 .

\section{Aspectos éticos}

Este trabalho foi aprovado pelo Comitê de Ética em Pesquisa da Feso (memorando 047/06), estando em concordância com o disposto na Resolução 196/96.

\section{RESULTADOS}

Durante o período avaliado — 1999 a $2004-, 669$ estudantes cursaram o Internato de Clínica Médica da Feso, dos quais 606 fizeram o PTG e a PM, caracterizando uma perda de $9,4 \%$. As médias do PTG e da PM realizados pelos 606 internos foram, respectivamente, 4,1 e 6,7 - apontando um crescimento de $63 \%$ (Gráfico 1 ).

Ao se analisarem as diferenças entre as médias do PTG e da PM, estratificando-se os resultados obtidos por ano, os resultados apontam, igualmente, um importante crescimento (Gráfico 2).

\section{GRÁFICO 2}

Série histórica comparativa das médias resultados do PTG e da PM no Internato de Clínica Médica da Feso de 1999 a $2004(n=606)$.

\begin{tabular}{|l|l|l|l|l|}
\hline & pré-teste \\
$\square$ prova final \\
\hline
\end{tabular}


A elevação da média da PM em comparação ao PTG é reflexo, em última análise, do melhor desempenho dos estudantes no segundo momento de avaliação, como demonstrado na Tabela 1.

TABELA 1

Pré-teste e prova final: média, desvio-padrão e teste de significância - Internato de Clínica Médica, Fundação Educacional Serra dos Órgãos (Feso), 1999-2004

\begin{tabular}{cccccc}
\hline Período & \multicolumn{2}{c}{ Média } & \multicolumn{2}{c}{ Desvio-padrão } & $\begin{array}{c}\text { p-valor } \\
\text { (teste t- } \\
\end{array}$ \\
& PTG & PM & PM & PM & Student) \\
\hline $1999(\mathrm{n}=49)$ & 4,2 & 7,5 & 1,38 & 1,64 & $<0,0001$ \\
$2000(\mathrm{n}=35)$ & 4,1 & 6,6 & 1,29 & 1,34 & $<0,0001$ \\
$2001(\mathrm{n}=110)$ & 5,1 & 6,8 & 1,93 & 1,22 & $<0,0001$ \\
$2002(\mathrm{n}=116)$ & 4,0 & 6,5 & 1,21 & 1,28 & $<0,0001$ \\
$2003(\mathrm{n}=150)$ & 4,1 & 6,8 & 1,66 & 1,36 & $<0,0001$ \\
$2004(\mathrm{n}=147)$ & 3,5 & 6,3 & 1,43 & 1,47 & $<0,0001$ \\
\hline
\end{tabular}

Esta constatação pode ser ratificada ao se comparar o número de internos que obtiveram grau igual ou superior a cinco nos testes, como apresentado na Tabela 2.

TABELA 2

Comparação do número de internos que obtiveram grau $\geq 5,0$ no PTG e na PM

\begin{tabular}{lcc}
\hline \multicolumn{1}{c}{ Avaliação } & Nota $>$ 5,0 & Nota $<5, \mathbf{0}$ \\
\hline Prova de Módulo & 544 & 62 \\
Pré-Teste Geral & 170 & 436 \\
\hline
\end{tabular}
$\mathrm{p}<0,01$

Se é considerada como "ponto de corte" média igual ou superior a seis, os resultados mantêm a tendência (Tabela 3).

TABELA 3

Comparação do número de internos que obtiveram grau $>6,0$ no PTG e na PM

\begin{tabular}{lcc}
\hline \multicolumn{1}{c}{ Avaliação } & Nota $>\mathbf{6 , 0}$ & Nota $<\mathbf{6 , 0}$ \\
\hline Prova de Módulo & 431 & 175 \\
Pré-Teste Geral & 76 & 530 \\
\hline
\end{tabular}

$\mathrm{p}<0,01$

Em ambos os casos houve significância estatística $(\mathrm{p}<0,01)$.

\section{DISCUSSÃO}

A avaliação do estudante de Medicina - tema deste estudo - e do ensino médico como processo global permanece um assunto polêmico e sujeito a intensos debates, provavelmente pela inadequação dos métodos existentes e pelas transformações em curso nos currículos das escolas médicas do País, como demonstrado em recentes publicações ${ }^{6,7}$.

Estudo realizado pela Comissão Interinstitucional Nacional de Avaliação do Ensino Médico (Cinaem), em 1999, envolvendo 60 escolas médicas brasileiras e 22 mil estudantes, verificou que havia um crescimento cognitivo de $25 \%$ ao final do curso, com relação à entrada na escola médica ${ }^{8}$. Em outra ocasião, em 1997, a mesma Cinaem, ao realizar uma avaliação do crescimento cognitivo no internato, que envolveu 41 escolas e cerca de 2 mil internos, constatou que, ao se comparar o percentual de acerto em testes realizados no início e no final do internato, houve um incremento de cerca de $31 \%{ }^{9}$. Neste último estudo, os internos obtiveram a média 3,9 no teste inicial e 5,1 no teste ao término do período. Estavam envolvidas todas as áreas básicas do internato: Clínica Cirúrgica, Pediatria, Ginecologia-Obstetrícia, Saúde Coletiva e Clínica Médica. Na área de Clínica Médica, que é a do presente estudo, o crescimento foi próximo de $\mathbf{3 0} \%$ (inferência a partir de imagem gráfica, já que não estão explicitados os valores relativos a cada área). Naquela ocasião, o curso de Medicina da Feso recebeu um relatório próprio, que avaliava o crescimento cognitivo dos nossos internos. Verificou-se que, no internato de Clínica Médica, eles obtinham a média de 33,27 ao início e saiam com 34,71 , caracterizando um crescimento de $4,3 \%$. Deve-se revelar, no entanto, que esta avaliação envolveu apenas 14 internos da instituição. Embora suspeitando que neste processo tenham sido selecionados discentes com melhor qualidade, parece ser quase impossível considerar seus resultados, em virtude da pequena amostra ${ }^{10}$. Um Teste do Progresso da Universidade Federal de São Paulo (Unifesp), realizado em 1998, mostra que os alunos do primeiro ano têm 32\% de acerto, enquanto os do sexto ano ficam com $58 \%$. Isto mostra um progresso - em termos de crescimento cognitivo - de $\mathbf{2 6} \%$ ao longo dos seis anos.

Na presente investigação, verifica-se um crescimento de cerca de $\mathbf{6 3} \%$ na média de acertos no teste inicial, comparada com a obtida no teste ao final do internato de Clínica Médica. Com base nesses dados, foram feitas duas constatações: (1) o interno da Feso está chegando com melhor acúmulo cognitivo (41\% versus 39\% da Cinaem-Brasil, 1997 e 33,27\% da Cinaem-Teresópolis, 1997) ${ }^{9,10}$ e (2) tem um crescimento que é quase o dobro dos que até agora foram publicados.

\section{CONSIDERAÇÕES FINAIS}

Os autores se inspiraram no movimento Cinaem, infelizmente abortado pelas dificuldades de diálogo entre os di- 
ferentes representantes das instituições que a compunham, considerando a avaliação um instrumento indispensável para romper com a inércia e apontar mudanças na escola médica.

As conclusões apresentam, entretanto, algumas dificuldades: o instrumento utilizado pela Cinaem, um teste de múltipla escolha, continha maior número de questões e não tinha perguntas discursivas; o da Unifesp também continha um número muito maior de questões. O primeiro foi elaborado por docentes externos, e o outro por docentes da própria instituição. $\mathrm{O}$ teste de crescimento cognitivo durante o ICM, realizado pela Cinaem em 1997 na Feso, envolveu apenas 14 internos, uma amostra muito pequena e com um viés de seleção. Os testes que compunham as avaliações ora apresentadas continham questões que, por serem formuladas por docentes da instituição, têm maior probabilidade de serem familiares aos próprios discentes. Contudo, os dois momentos têm estas mesmas características, e isto aumenta a propensão a se acreditar que houve, durante o ICM, um real crescimento cognitivo dos estudantes. Outra dificuldade para tornar os grupos comparáveis é o tempo de internato em cada área nas diversas instituições: três meses na Feso e, às vezes, seis meses em outras.

Apesar das críticas ao teste de crescimento cognitivo realizado pela Cinaem em 1997, não foi possível resistir ao desejo de assinalar que o crescimento de $4,3 \%$ revelado naquela ocasião - caso pudesse, incontestavelmente, ser comparado aos atuais $63 \%$ - parece, de algum modo, apontar para todo o trabalho construído no período destas observações, porque, justamente em 1998, houve uma grande transformação no internato da Feso, na qual foram lançadas as bases que ainda orientam o atual modelo de organização e de trabalho.

\section{AGRADECIMENTOS}

Os autores não poderiam deixar de externar seu profundo agradecimento aos queridos estudantes, que têm concedido à equipe do ICM o grande privilégio da convivência, do aprendizado e do afeto.

\section{REFERÊNCIAS}

1. Santos SS, Siqueira-Batista R. Avaliação cognitiva no internato médico: experiência da disciplina de Clínica Médica, Faculdade de Medicina de Teresópolis, Fundação Educacional Serra dos Órgãos (FESO). Rev Bras Educ Med 2003; 27(3): 223-8.

2. Lo B. Questões éticas na medicina clínica. In: Braunwald E, Fauci AS, Kasper DL, Hauser SL, Longo DL, Jameson JL. Harrison Medicina Interna. 15 $\mathrm{a}$ ed. Rio de Janeiro: Guanabara Koogan, 2002.
3. Luckesi C. Avaliação educacional: pressupostos conceituais. Tecnologia Educacional 1978; 7(24):5-8.

4. Jozefowicz RF, Koeppen BM, Case S, Galbraith R, Swanson D, Glew RH. The quality of in-house medical school examinations. Acad Med 2002 Feb;77(2):156-61.

5. Soares JF, Siqueira AL. Introdução à estatística médica. Belo Horizonte: Departamento de Estatística - UFMG, 1999.

6. Marins JJN, Rego S, Lampert JB, Araújo JGC. Educação médica em transformação: instrumentos para a construção de novas realidades. São Paulo: Hucitec; Rio de Janeiro: Associação Brasileira de Educação Médica, 2004.

7. Feuerwerker L. Além do discurso de mudança na educação médica: processos e resultados. São Paulo: Hucitec; Londrina: Rede Unida; Rio de Janeiro: Associação Brasileira de Educação Médica, 2002.

8. Piccini R, Facchini R, Santos R orgs. Preparando a transformação da educação médica brasileira: Projeto Cinaem III Fase: Relatório 1999-2000. Pelotas: Ufpel; 2000. p. 259-60

9. Silva AR, Oliveira RA, Amaral JL. Os formandos das escolas médicas brasileiras - estudo de coorte. In: CINAEM, avaliação do ensino médico no Brasil. Relatório Geral 1991-1997.

10. Piccini RX, Facchini LA, Tomasi E, Maia MFS, Ambrosio MAD. Projeto CINAEM: relatório do Curso de Medicina do Centro de Ciência da Saúde de Teresópolis (RJ). 1997

11. Borges DR, Stella RCR. Avaliação do ensino de medicina na Universidade Federal de São Paulo. Rev. Bras. Educ. Med. 1999;23(1):11-17.

\section{CONFLITOS DE INTERESSE}

Declarou não haver

\section{ENDEREÇO PARA CORRESPONDÊNCIA}

Sávio Silva Santos

Rua Rio Grande do Norte, 229

Araras - Teresópolis

CEP.25958-220 / RJ

E-mail: saviossilva@hotmail.com 